disease, which must occupy at least a fortnight in its progess, before it can be decided to be quite satisfuctory, and during that period the individual is liable to suffer in. terruption of the sanatory process fiom va. rious causes, sufficient to place him in a very doubtful position, to say the least, as to future immunity from small-pox. Therefore, the disease, to give the satisfactory security which is desired, and which should be required as far as possible by the Bill now pending, should be examined, and, to secure this watching and examination, should be reported in a certain given number of the stages of its progress. And who, I would ask, are competent to the task of receiving and checking these returns, and rendering them available to the purposes of medical science, but medical men? To what purpose is it to give, according to the wording of the Act, a report of the vaccinated? How would science be forwarded, or correct practice be secured by the statement, that since such a day 250 or 2000 persons were vaccinated? Would it not be a saving of time and trouble to leave the whole responsibility as it now is, with the boards of guardians, who are at hberty at any time to compel the union surgeons to vaccinate the paupers?

But to proceed with the details of my proposed plan. Having organised an efficient central board, I would appoint, thronghout the kingdom, districts, and to each of these districts a vaccinator. These districts should be large enough to be subdivided into three or four parts, in the centre of each of which divisions should be a station; thus the vaccinator could give his attendance to these stations on different days of the week, and might thus take the vaccine charge of a district of considerable size. At the time of vaccination he should be required to report certain given particulars of each case, and the fee appointed for each case should not be allowed, or only a part of it, if the report of the case is not continued, at least to the eighth day after vaccination. To encourage a spirit of emulation, or the correctness and fulness of the reports, let annual prizes be publicly awarded to the most meritorious vaccinators. This will be an inducement to the individuai vaccinator to pay particular attention to, and to give a full report of all the anomalies and varieties that he may meet with, as well as every circumstance which may be calculated to throw light on the subject. With a well-organised plan of operation, and a faithful system of reports, what a valuable mass of statistical information would be soon collected! and how much light might we not thus throw upon most important subjects, the investigation of which we are at present content to leave in the hands of others!

I would suggest that the inoculation of small-pox shall be forbidden under a heavy penalty, except by medical men, whose good seuse and right feeling would be a sufficient guarantee against making it a gene. ral practice, and who might yet meet with occasions in which they would feel justified in departing from the general rule.

In conclusion, I would only add, that it wonld afford me great satisfaction if I might hope, that any thing I have now said would throw any light upon a subject, interesting to every individual, though, I fear, not sufficiently studied or understood by the framers of the Bill now in progress through Parliament. So convinced do I feel of its insufficiency for the ohject in view, that I would say, rather than have this, let us re. main as we are, until the measure of general medical reform, which must ere long re. model our profession, shall enable us to place vaccination on the footing which its importance certainly merits. I am, Sir, \&\&. A. T. S. D Secretary to the Vaccination Section of the Provincial Medical Association.

Chichester, May 2nd, 1810.

\section{RESTRAINT OF INSANE PERSONS.}

\section{To the Editor of THE LANCET.}

Sir :-Your correspondent, Mr. Hill, appears determined to urge me into controversy, and obligingly commends my candour, for which I thank him; I am, however, sorry I cannot quite concede to him the same complimentary admission.

In my former letter, I stated "I had cartfully questioned the patients, both between the paroxysm 3 and after recovery, and had found them, with very few exceptions, un. hesitatingly prefer restraint to the terror and irritation of surveillance ;" to which Mr. H. replies, " the whims and perverted instinets of lunatics are notorious, and ought not to be indulged." I think not either, yet I cannot but incline to the opinion, that had such testimony been in favour of Mr. H.'s system, he would have maintained, as I do, that the preference, even of a lunatic, in a matter affecting his own personal feeling, shonld be respected. At any rate, he is not likely to choose that which is most painful to himself; but the deliberate opinion of convalescent and cured patients, on such a foint, is of the first importance.

If perfect liberty be given to a dangerons lunatic, Mr. H. says, "he soon exhausts his mental irritability." How soon? In nine cases out of ten just so soon as the physical powers sink under his frenzied exertions, or, in other words, he ceases to vociferate, because be is so hourse he cal scarcely speak; he ceases to. kick and strike, because his arms and legs are power. less, and covered with bruises; and he lays his weary head on the pillow, tranquil from sheer exhaustion. 
I should judge Mr. H., in his praiseworthy zeal, has never tried any system but his own. The word exbaust appears illadapted to our object. We have to allay irritation, to soothe, to tranquillize. Now I maintain that the liberty which the poor, distracted creature only knows how to abuse, tends to keep up the mental irritability.

Mr. H. observes, that " accidents will sometimes happen in a lunatic asylum, and attendants will be occasionally irritated into striking a patient; but such accidents will be found much more aumerous where restraints are most numerous."

Facts do not appear to bear out this statement; I think they rather tend to prove the very reverse.

In some public institutions with which I am acquainted, the instances of servants discharged for maltreatment are rare. In this asylum, during ten years, only two have been dismissed on this account.

The novel idea of awing a lunatic into submission, by the presence of an attendant so fearfully large, that he dares not even attempt competition, and that large men are better tempered than little ones, is curious enough. For my own part, I have never found anything more than good common sense and sterling principle as indispensably requisite in servants; $I$ believe we shall be better aided in our endeavours by the judicious assistant, possessed of that peculiar tact which can be acquired only by a pracsical acquaintance with the treatment of the insane, whatever his stature may be, than by the presence of a whole host of giants.

From a multitude of cases, illustrative of the value of judicious restraint, furnished by the journals of this institution, I select one which may be considered sa a sample of the rest.

Some years ago U. D. was admitted into this asylum; although he had received a liberal education, and moved in a rank of society much above that for which this place is destined, irregularities and misfortunes had brought him to the condition of a pauper. He was a young and handsome man, full six feet three inches in height, and proportionably athletic, and well-made; previous to his admission he had been confined a year in two different lunatic asylums, from both of which his removal was hailed with joy, and he had made some desperate attempts on the lives of his relatives. On his admission his ravings consisted of a volley of obscenity and blasplemy, whilst every one who came in his way, windows, furniture, \&c., were objects of his violence. With the concurrence of my able coadjutor, the visiting physician, the sleeves were placed on him;* he was fastened into bed,

* I was not without my suspicions of a habit which would have counteracted all our efforts. and light totally excluded from his apartment (I suppose Mr. H. would hold up his hands in astonishment). From the flushed countenance, and the full action of the carotids, leeches were applied to the temples, gentle aperients and sedatives were administered. In a few days the irritability subsided ; but light, sound, and the presence of any one, renewed it. In this state he remained a month, and was going on favourably; he slept better, and could converse colerently for a short time, when the visit of a relation renewed the attack in all its violence, and we had the same ground to go over again. In a short time the light was admitted by degrees; he spoke rationally, but with some excitement of mauner; was unrestrained, and allowed to walk alone in the gallery. In five months he was perfectly cured, and remembered, with extraordinary distinctness, nearly every circumstance that had occurred, and apologised for his condact to the Visiting Physician and myself in a manner truly touching. He explained to me the effect that his own efforts, light, and sound had conspired to produce in keeping up the excitement, and considered the salutary restraint to which he had been subjected the cause of his recovery.

I am happy to add, he has become a highly-respectable meniber of society; he has prospered in the world, fills with credit the station of a gentleman, and has twice visited the asylum since his liberation.

I know so well the difficulties which encompass the path of the superintendent of a lunatic asylum,* the liability of his best exertions to misrepresentation, his exposure to attacks emanating only from feelings of personal malignity, and motives of which every honest man would be ashamed; the fetty cavillings and opposition he is often called to undergo from those who wrap themselves up in fancied notions of their own excessive wisdom, and practically know nothing; whilst censure, the lowest exercise of the understanding, is considered as fairly employed on him, by would-be authors, devoid of talents capable of any higher range; and feeling this, it is with delicacy $I$ allude to the Lincoln Asylum. Withoutparticularising my motives I would merely remark, that the very frequent change of officers and servants in that institation, does not speak much for the working of the system.

I would say of a public institution as of a private family, where such changes are unusually frequent, your fault is less in your men than your system. Look to it that

* Who in such a situation has not felt the full force of Esquirol's exclamation,-Qwe peut espérer un médecin qui a toujours tort quand il ne réussit pas, qui a rarement raison quand il a du succès, et qui est poursuivi por les prejug'es même dans le bien qa'il a obtenu? 

your mainspring be not wrong; you are
perpetually introducing novices, by which the interest is broken, and confidence destroyed, and no sooner do they become ini. tiated in the discharge of duties, the most difficult to which man or woman in any station of life can be called, than the benefit of their experience is lost to the patients, and other novices take their place.

The superintendent of a lunatic asylum requires to have his zeal tempered by extra. ordinary prudence, his exertions supported by extraordinary coolness and patience, otherwise he will only increase his difficul. ties until they are altogether insurmountable.

I have merely to say, in conclusion, that when, instead of confusion and discomfort, officers ever going and coming, and numerous servants discharged for maltreatment of patients, we shall find those institutions which boast the total abolition of restraint return the largest proportion of cures, and shall have sufficient evidence that the unfor. tunate inmates are healthier and happier than any others; then, and not until then, will it be time for me, and a host of my respected medical brethren, to acknowledge the system is not a piece of contemptible quackery - a mere bait for the public earbut really a valuable improvement in science, for which the originators well deserve from the medical profession, and the insane world at large, the warmest thanks and the most profound respect.

I have to apologise for trespassing at such length on your useful columns; the importance of the subject must be my excuse. I have the honour to be, Sir, your obedient and faithful servant,

Lunatic Asylum, Wakefield, C. C. Corsellis, M.D. April 24tb, 1840.

\section{OPERATION FOR SUBCLAVIAN} ANEURISM.

\section{To lhe Editor of ThE Lancet.}

Sir :-In The Lancet of May 2ad I observe some remarks on the subject of ligature of the subclavian artery; in which the writer states his belief, that in the cases of aneurism of the subclavian, external to the scalenus, operated on by Mr. Liston by ligature of the vessel internal to the muscle, the operation should have been performed where the artery passes under the muscle.

If the author had had an opportunity of examining cases of aneurism of the third part of the course of the artery, and commencing inmediately external to the scalenus, he would have found that an incision over this muscle, and the dissection to expose it, could not be made without wounding the sac of the aneurism. The space between the tumour and the internal jugu- lar vein does not exceed a quarter of an inch; an operator is ignorant of the thick. uess of the parietes of the sac, and I defy the most skilful to pass a ligature round the artery, so closely in contact with $s 0$ large a tumour, as the one last recorded in The Lancet, without cutting into the sac.

It is in cases of aneurism in the axillary extending very high up, that the operation under the scalenus muscle has succeeded; but I think few would be suficiently hardy to propose such an operatiou who had once seen and examined in the living body the re. lative position of the parts in aneurism of the third part of the course of the vessel. In the two cases operated on by Mr. Liston, the operation internal to the scalenus was the only one that could be undertaken, Only one case of ligature of the subclavian in this situation had been recorded; and as in operation on other arteries many of the first cases were unsuccessful, it was hoped that another favourable trial might place this among the admitted operations in sur. gery. I am, Sir, your obedient servant,

London, May 5, 1840. AN Old Dresser.

\section{POTASSA FUSA IN STRICTURES OF THE URETHRA.}

To the Editor of THE LANCET.

SIR :-Although two months have elapsed since the discussion to which the annexed paper refers was pablished in your Perio. dical, you will oblige me by inserting it in one of your earliest Numbers. My atten. tion was not called to the subject until of day or two ago, and although late in my notice of it, $I$ cannot forbear doing so, in justice to the memory of my late respected father, whose talents and benevolence are still well-remembered by many. I am, Sir, your obedient servant,

Thos. Whately, M.R.C.S.

Berkhampstead, April 22ad, 1840.

In the notice of the proceedings of the Westminster Medical Society, published in THE LANCET of the 22nd of February last, I perceive that Mr. Robert Wade read a paper on the application of the potassa fusa to strictures of the urethra, which paper, from its leaving unnoticed the beneficial results obtained by others from this practice, would lead any cursory reader to suppose, that he (Mr. Wade) was the first introducer of it, and that it was a new and original uppliance in his hands. Mr. Wade omitted to mention the name of my late father, who was the first who proposed and applied the caustic potash to strictures of the urethra, and pub. lished a work upon the practice, the third and last edition of which was published with many additions in 1817 ; it was first published in 1805. Mr. Abernethy used to re- 